\title{
Arc Flash Boundary Calculations Using Computer Software Tools
}

\author{
Mark D. Gibbs
}

Presented at the: IEEE Industry Applications Society (IAS) 2004 Annual Meeting

Seattle, Washington

October 3-7, 2004

DATE OF ISSUE: JANUARY 7, 2005

Prepared by the

Y-12 National Security Complex

P.O. Box 2009

Oak Ridge, Tennessee 37831-8169

managed by

BWXT Y-12 L.L.C.

for the

U.S. Department of Energy

Under contract DE-AC05-22800 


\section{DISCLAIMER}

This report was prepared as an account of work sponsored by an agency of the United States Government. Neither the United States Government nor any agency thereof, nor any of their employees, makes any warranty, express or implied, or assumes any legal liability or responsibility for the accuracy, completeness, or usefulness of any information, apparatus, product, or process disclosed, or represents that its use would not infringe privately owned rights. Reference herein to any specific commercial product, process, or service by trade name, trademark, manufacturer, or otherwise, does not necessarily constitute or imply its endorsement, recommendation, or favoring by the United States Government or any agency thereof. The views and opinions of authors expressed herein do not necessarily state or reflect those of the United States Government or any agency thereof.

\section{COPYRIGHT NOTICE}

"The submitted manuscript has been authored by a contractor of the U.S. Government under contract DE-AC05-00OR22800.

Accordingly, the U.S. Government retains a paid-up, nonexclusive, irrevocable, worldwide license to publish or reproduce the published form of this contribution, prepare derivative works, distribute copies to the public, and perform publicly and display publicly, or allow others to do so, for U.S. Government purposes." 


\title{
Arc Flash Boundary Calculations Using Computer Software Tools
}

\author{
Mark D. Gibbs, Member, IEEE \\ BWXT-Y12 \\ Electrical Engineering Department \\ Oak Ridge, TN USA
}

\begin{abstract}
Arc Flash Protection boundary calculations have become easier to perform with the availability of personal computer software. These programs incorporate arc flash protection boundary formulas for different voltage and current levels, calculate the bolted fault current at each bus, and use built in time-current coordination curves to determine the clearing time of protective devices in the system. Results of the arc flash protection boundary calculations can be presented in several different forms - as an annotation to the one-line diagram, as a table of arc flash protection boundary distances, and as printed placards to be attached to the appropriate equipment. Basic arc flash protection boundary principles are presented in this paper along with several helpful suggestions for performing arc flash protection boundary calculations.
\end{abstract}

\section{INTRODUCTION}

Electrical Arc Flash is the passage of current between two electrodes through ionized gases and vapors. The electrical energy supplied to the arc is converted into other forms of energy, resulting in intense thermal radiation, noise, explosive expansion of surrounding air due to rapid heating, and melting/vaporization of arc electrodes and metal components in the vicinity of the arc. An electric arc flash occurs when the insulation between the conductive components can no longer withstand the applied voltage. According to a technical paper by Ralph Lee, "The extremely high temperatures of these arcs can cause fatal burns at up to about 5 feet and major burns at up to about 10 feet distance from the arc. Additionally, electric arcs expel droplets of molten terminal material that shower the immediate vicinity, similar to, but more extensive than that from electrical arc welding".

Arc flash is primarily found in circuits of 208 and higher voltages in commercial and industrial facilities. Protection from arc flash is a personnel safety issue. It is summarized in the 2002 edition of the NFPA National Electrical Code handbook: "Field markings that warn electrical workers of potential electrical arc flash hazards are now required because significant numbers of electricians are being seriously burned or killed from accidental electrical arc flash while working "hot" (energized) equipment. Most of these accidents could be prevented, or their severity significantly reduced, if electricians wore the proper type of protective clothing.
Requiring switchboards, panelboards and motor control centers to be individually field-marked with proper warning labels will raise the level of awareness of electrical arc flash hazards and thereby decrease the number of accidents".

Arc Flash Protection boundary calculations have become easier to perform with the availability of personal computer software. These programs include arc flash protection boundary formulas for different voltage and current levels, calculate the bolted fault current at each bus, and use timecurrent coordination curves to determine the clearing time of the protective devices in the system. One of the benefits of using a computer is that the clearing time of the breakers is automatically calculated for any changes in equipment settings that affect the bolted fault current. This feature saves time by eliminating graphical determination of clearing times. A step by step method for calculating arc flash protection boundaries with the aid of a software program is subsequently outlined. For a more in depth look at arc flash protection boundary calculations see IEEE Standard 1584-2002.

\section{ARC FLASH CALCULATION METHODOLOGY}

\section{A. Determine System Configuration}

Making an electronic model of the system is the first step in performing an Arc Flash Protection Boundary calculation. The electronic model can be built from available one-line diagrams or from collecting field data. The minimum equipment data that is needed for building the electronic model is shown in Table 1.

The fault MVA and the protective device clearing time drive arc flash calculations. Whereas maximum faults are normally used for equipment selection, minimum faults often represent the worst case for arc flash. The fault MVA dominates at larger magnitudes of fault current while breaker clearing time dominates at lower fault MVA magnitudes. This relationship is illustrated for a $100 \mathrm{amp}, 480 \mathrm{~V}$, Square D, Type KA circuit breaker in Figure 1. This relationship exists because the circuit breaker takes a relatively long time to trip at low magnitudes of fault current while it trips almost instantaneously at higher magnitudes of fault current. This relationship holds true over the range of fault current the circuit breaker (or other device, such as a fuse) is rated to 
interrupt. Fault currents in excess of the circuit breaker interrupting rating can result in catastrophic failure.

Table 1: Minimum Equipment Data

\begin{tabular}{|l|l|}
\hline Component & Attributes \\
\hline Utility & $\begin{array}{l}\text { SC Contribution } \\
\text { Initial Voltage } \\
\text { X/R 3 Phase }\end{array}$ \\
\hline Transformers & $\begin{array}{l}\text { Nominal kVA } \\
\text { Primary Voltage } \\
\text { Secondary Voltage } \\
\text { \%Z Impedance }\end{array}$ \\
\hline Conductors & $\begin{array}{l}\text { Size (AWG) } \\
\text { Length } \\
\text { Qty per Phase } \\
\text { Conductor Material } \\
\text { Duct Material }\end{array}$ \\
\hline Breakers & $\begin{array}{l}\text { Model } \\
\text { Trip or Sensor Setting }\end{array}$ \\
& $\begin{array}{l}\text { The following attributes } \\
\text { are needed as they apply } \\
\text { to the particular breaker. } \\
\text { Plug } \\
\text { LTPU } \\
\text { LTD } \\
\text { STPU } \\
\text { STD } \\
\text { INST }\end{array}$ \\
\hline Fuses & $\begin{array}{l}\text { Model } \\
\text { Trip }\end{array}$ \\
\hline Nominal HP \\
\hline
\end{tabular}

Collection of accurate equipment data is the most important step in performing an Arc Flash Protection Boundary calculation. Wire and cable lengths have to be determined as precisely as possible since their impedance can have a dramatic effect on the short circuit current. For example, if CBL-MAIN in Figure 2 is 300 feet, the trip time of breaker MAIN is 0.03 seconds. If CBL-MAIN is increased in length to 400 feet, the trip time of breaker MAIN is 24.506 seconds, a difference of 24.476 seconds. The increase in cable length also increases its impedance resulting in an attendant decrease in fault current. The circuit breaker will operate in the magnetic (instantaneous) region for a cable length of 300 feet, but it will operate in the thermal region for a cable length of 400 feet. This will result in the Arc Flash Protection Boundary changing from 5.52 inches to 306.42 inches, a significant change in the Arc Flash Protection Boundary for this example and a significant increase in the potential hazard to personnel.

A system configuration that requires special attention is when the protective device is at a different voltage level than the point of work. Service entrances are a common example of this occurrence - the first upstream protective device is often located on the primary side of the transformer to which the service drop is connected. The Arc Flash Protection Boundary will be larger because the protective device is applied at a higher voltage level and has a longer trip time.

\section{B. Running the Arc Flash Protection Boundary Study}

Select the appropriate icon from the programs' arc flash menu to launch the module. Study options can include, but are not limited to: the standard to which the calculation is done (NFPA 70E or IEEE 1584), the units (English or metric units), type of fuses (current limiting or standard), induction motor fault contribution, and type of report. Other considerations when running the study include whether the system is grounded or ungrounded and the equipment type (open air, switchgear, panel/MCC, cable).

The program first calculates the bolted fault current at each bus in the system and finds the first upstream protective device from each bus. The program then retrieves the built-in timecurrent coordination curves to determine the protective device's clearing time and the appropriate arc flash protection boundary formula for the bus voltage and current level being examined. The Arc Flash Protection Boundaries are then calculated and tabulated for use in reports or on-screen viewing.

\section{View Results and Generate Labels}

The results of the Arc Flash Boundary calculation can be presented in various forms such as text documents, spreadsheets, and annotated one-line diagrams that can also be copied and pasted into reports. An example of an annotated one-line diagram is given in Figure 3. These computer programs can also generate flash hazard labels that can be applied to equipment in the field. An example of a flash hazard label for BUS-M1 is given in Figure 4. Note that specific Personnel Protective Equipment (PPE) requirements can also be included on the label generated by the software.

\section{CONCLUSION}

Arc Flash Protection boundary calculations have become easier to perform with the availability of personal computer software. The software determines the clearing time of protective devices from the calculated bolted fault current, thereby eliminating the once tedious task of finding manufacturer's published time-current curves and determining accurate clearing times for the bolted fault current from the published data. Arc Flash Boundary calculation results can be published in various forms such as text documents, spreadsheets, and annotated one-line diagrams. These results can be pasted into reports providing great flexibility in how information is presented. These computer programs can also 
generate flash hazard labels that can be printed to adhesive backed paper and applied to equipment in the field.

Following the steps outlined above, in conjunction with using one of the commercially available arc flash software programs, will make the task of assessing and controlling this common workplace hazard simpler, faster, and more effective.

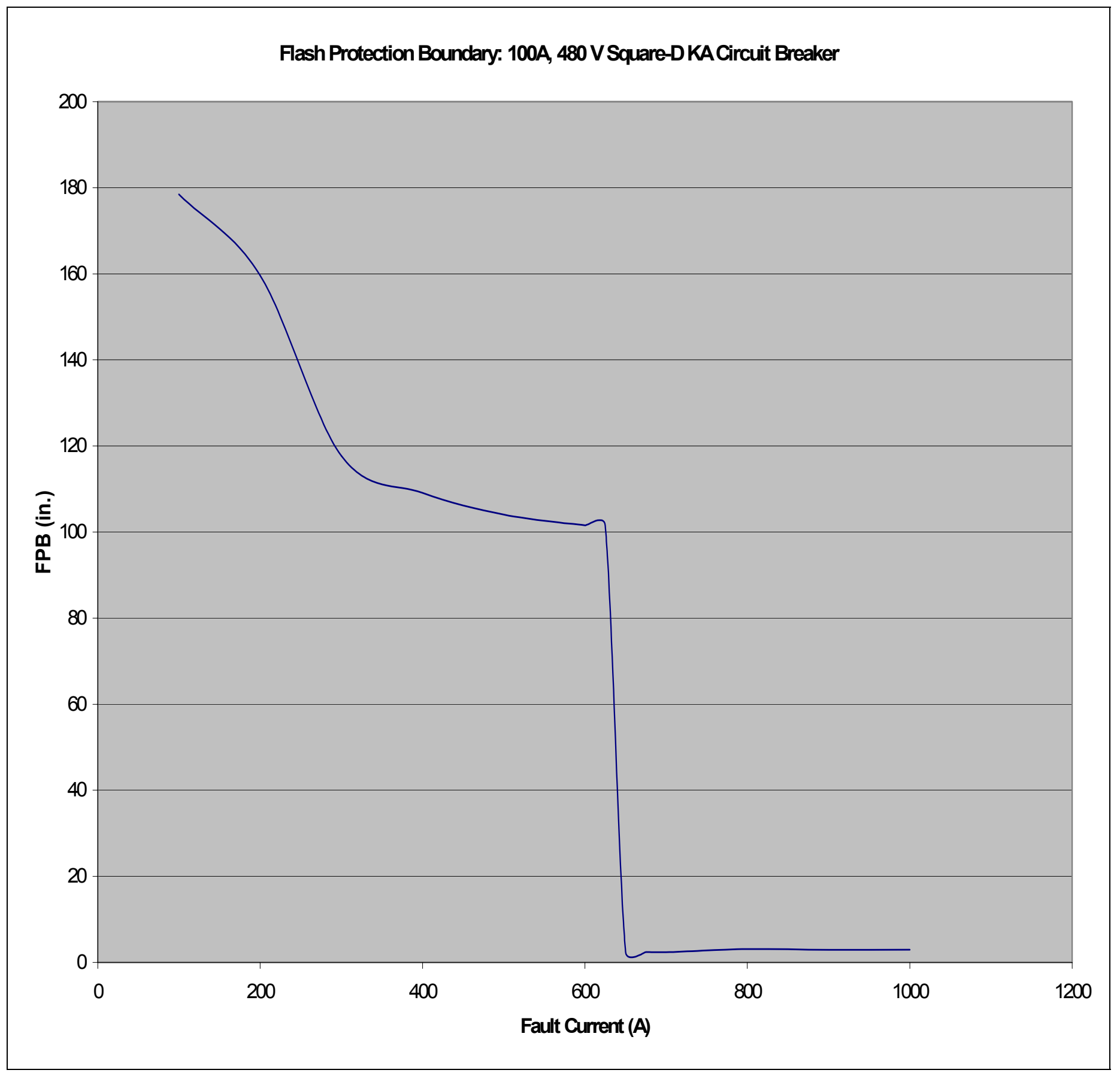

Figure 1. Flash Protection Boundary Square D KA Circuit Breaker. 


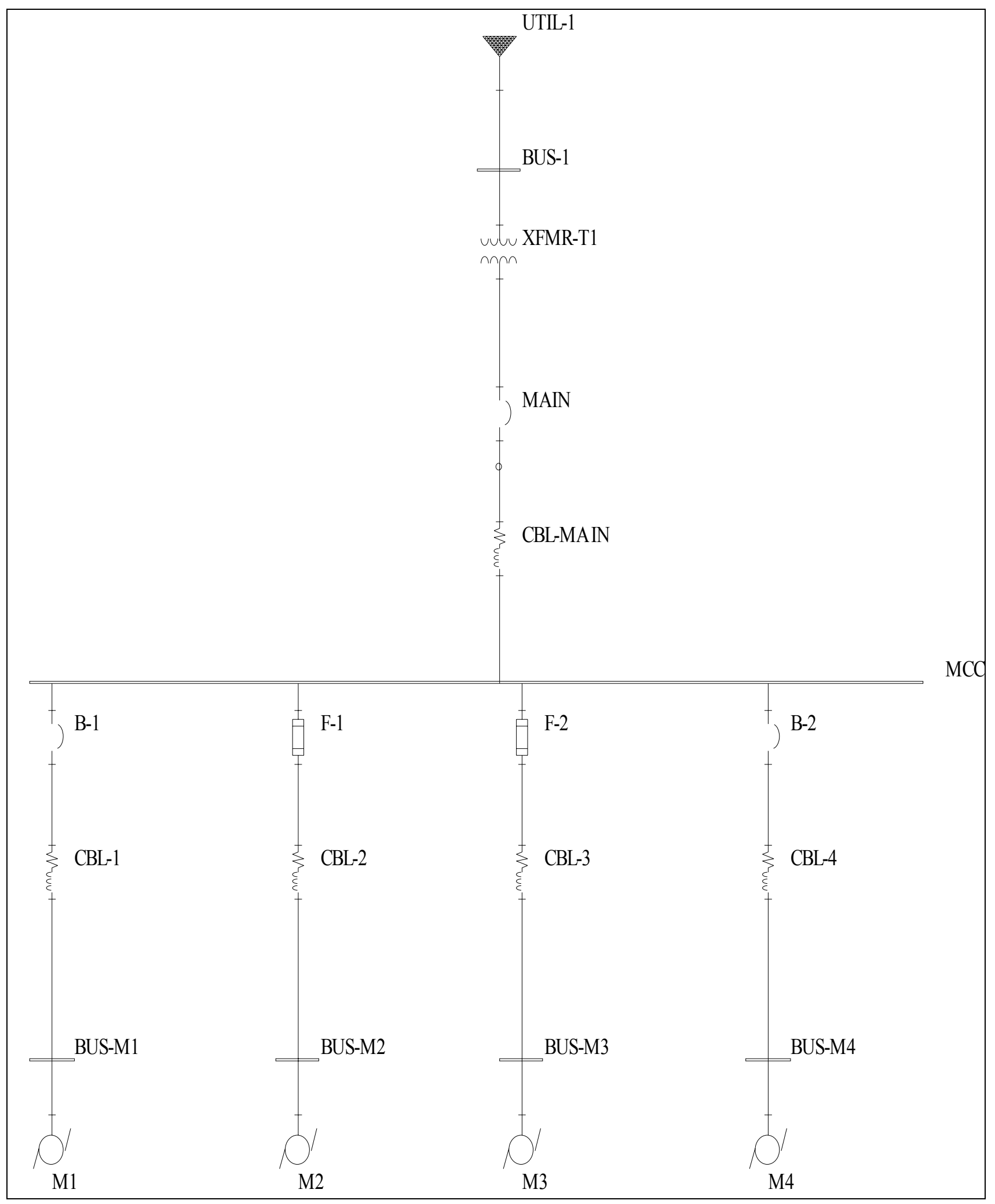

Figure 2. One-Line Diagram. 


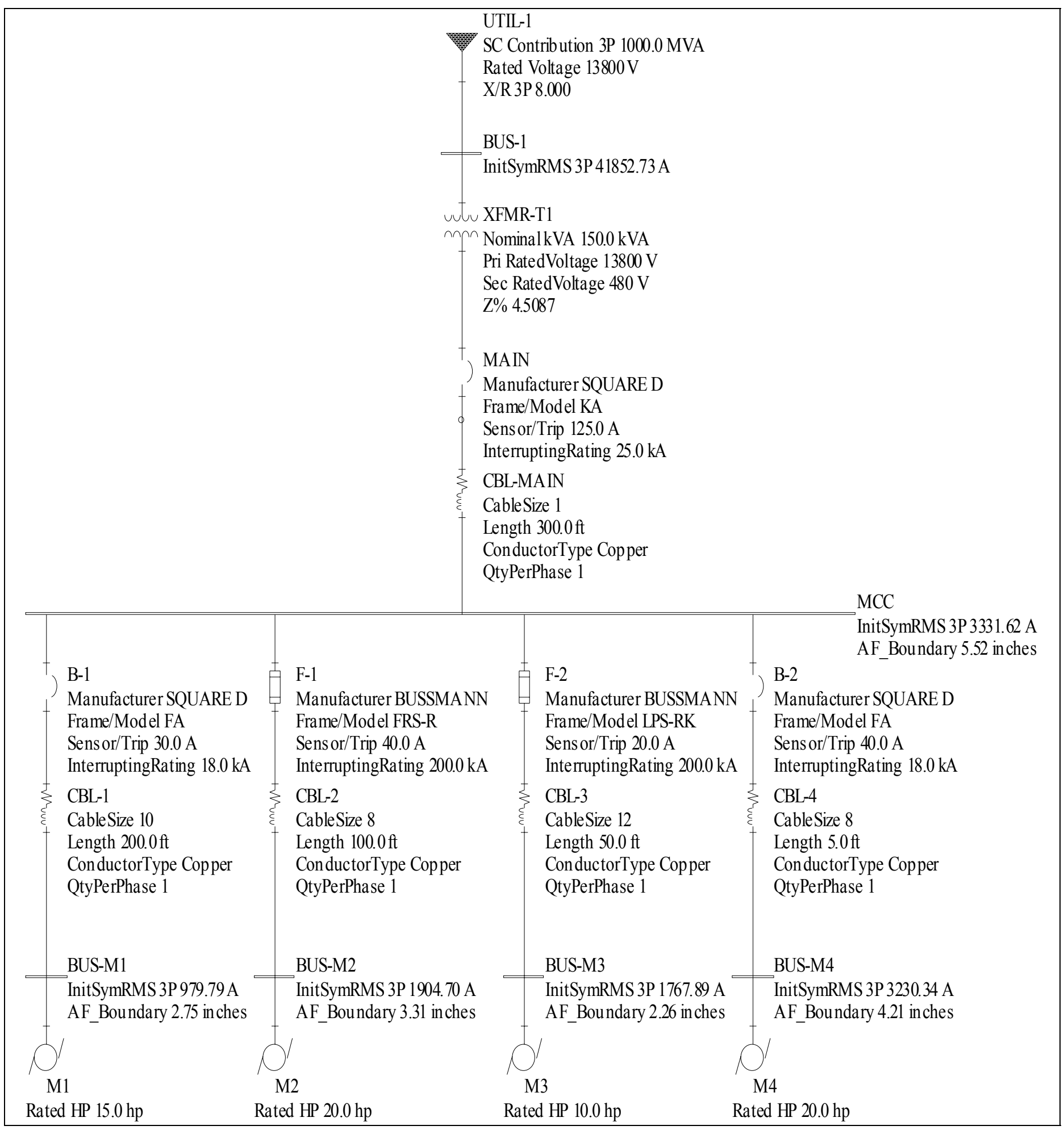

Figure 3. Annotated One-Line Diagram. 


\begin{tabular}{|l|l|}
\hline & \\
\hline 3 inch & Flash Hazard Boundary \\
0.03 & calcm^2 Flash Hazard at 24 inches \\
Class 0 & Untreated Cotton \\
$480 \mathrm{VAC}$ & Shock Hazard when cover is removed \\
42 inch & Limited Approach \\
12 inch & Restricted Approach \\
1 inch & Prohibited Approach \\
\hline Bus Name: & BUS-M1, Prot Device: B-1 \\
\hline
\end{tabular}

Figure 4. Flash Hazard Label. 